\title{
The Current and Future Potential Geographical Distribution of the Italian Locust, Calliptamus Italicus (Linnaeus) (Orthoptera: Acrididae) in China*
}

\author{
Yujia Qin ${ }^{1}$, Zhihong $\mathrm{Li}^{1, * * *}$, Li Zhao $^{2}$, Glenn Fowler ${ }^{3}$, and Yan Fang ${ }^{1}$ \\ ${ }^{1}$ Department of Entomology, China Agricultural University, Beijing 100193, P.R. China \\ ${ }^{2}$ College of Agronomy, Xinjiang Agricultural University, Wulumuqi 830052, P.R. China \\ ${ }^{3}$ USDA-APHIS-PPQ-CPHST-PERAL, 1730 Varsity Drive, Suite 300, Raleigh, NC 27606 \\ lizh@cau.edu.cn
}

\begin{abstract}
The Italian Locust, Calliptamus italicus (Linnaeus) (Orthoptera: Acrididae), is one of the most harmful species to the grasslands in Xinjiang province, China. It attacks a variety of plants in Compositae, Chenopodiaceae and Gramineae. We used CLIMEX and ArcGIS to determine the potential geographical distribution of $C$. italicus in China under current and future climatic scenarios. Our analysis predicted that under current climatic conditions, $C$. italicus has a wide potential distribution in areas north of the Yangtze River in China. With the climatic changes, the potential range for $C$. italicus was projected to expand, and the suitability levels of most areas would increase, especially in areas with optimal climatic conditions. We therefore suggest that surveys should be enhanced in the areas suitable for $C$. italicus to facilitate early detection and reduce potential damage.
\end{abstract}

Keywords: Callipatamus italicus (L), CLIMEX, ArcGIS, potential geographical distribution, climatic change.

\section{Introduction}

Callipatamus italicus (Linnaeus) is one of the main insect pests of grasslands in Xin Jiang, and attacks a wide range of host plants including 45 species in 17 families. The nymphs of $C$. italicus prefer Artemisia frigida Willd. and Carex onoei Franch. et Sav., while the adults prefer not only A. frigida Willd., but Salvia deserta Schang and Medicago falcate Linn. [1]. The Italian locust has become the most common and damaging plant pest in Kazakhstan, regularly invading millions of hectares and causing crop damage of great economic importance [2]. In 1999, Calliptamus italicus was introduced to from Kazakhstan and Russia into Xinjiang province, China. It subsequently damaged approximately 2 million hectares in 2000 and 2007 in Xinjiang province $[1,3]$.

\footnotetext{
* This study received financial supports from the Special Fund for Agro-scientific Research in the Public Interest (201003079).

** Corresponding author.
}

D. Li and Y. Chen (Eds.): CCTA 2012, Part II, IFIP AICT 393, pp. 290-298, 2013.

(C) IFIP International Federation for Information Processing 2013 
The distribution area of $C$. italicus stretches from Western Europe to the meadow-steppes of Central Asia in Siberia and in Kazakhstan and its neighboring countries. Its range includes countries along the northern and eastern edge of the Mediterranean Sea, Central Europe and Central Asia up to Mongolia and western Siberia [4]. These regions include the former USSR, Russia Federation, Spain, Italy, France, Ukraine, northern Africa; Siberia, Kazakhstan, Uzbekistan, Turkey, Mongolia, Iran, and Afghanistan. In China, it occurs in Xinjiang, Gansu, Qinghai, Shaanxi, and Hebei provinces [5, 6].

In this study we modeled the potential range of $C$. italicus in China based on climate suitability. Because pest ranges are likely to shift in response to changes in temperature and precipitation, we also assessed the effects of climatic change on its potential distribution.

\section{Materials and Methods}

\subsection{Overview Of CLIMEX Model and ArcGIS}

We used CLIMEX 3.0 to model the potential geographical distribution of C. italicus in China under current and future climate scenarios. CLIMEX model is a predictive modeling software that has been used to predict the potential geographical distribution of many pests including: Ceratitis capitata (Wiedemann) [7], Bactrocera zonata [8], Frankliniella occidentails Pergande [9], Hyphantria cunea [10], Solenopsis invicta [11], corynespora Leaf Fall Disease [12], Nassella neesiana [13].

CLIMEX is a dynamic model [14] that integrates the weekly responses of a population to climate using a series of annual indices. The model combines the growth index (GI) and the stress indices (SI) into an overall ecoclimatic index (EI). EI describes the climatic suitability of a location for a species as a number between 0 and 100. In this study, we classified the EI into four categories of climatic suitability for $C$. italicus: unsuitable $(\mathrm{EI}=0)$, marginal $(\mathrm{EI}=0-10)$, suitable $(\mathrm{EI}=10-20)$ and optimal $(\mathrm{EI}>20)[14,15]$.

To visualize the results, the CLIMEX output was 'loose-coupled' [15] to a geographical information system (ArcGIS). It can present CLIMEX results in the same map as a species distribution or other information that provides spatial context [16]. Both CLIMEX ver. 3.0 and Arc/INFO ver. 9.3 were purchased by the Plant Quarantine Lab of China Agriculture University.

\subsection{Meteorological Databases and Climatic Change}

Two climate databases were used in our model. We first used the CLIMEX standard meteorological dataset, based on 30 year averages from 1961 to 1990, to create an initial model output. This dataset contains information for 2500 weather stations worldwide. Secondly, we used a regular gridded dataset of the normal climate for the same period, TYN SC 2.0 (http://www.cru.uea.ac.uk/ timm/grid/TYN_SC_2_0.html) [17] to fine-tune the model output. The dataset consisted of 67,420 weather stations 
spaced on a $0.5^{\circ}$ latitude $\times 0.5^{\circ}$ longitude regular grid for significant land areas worldwide.

For the climate change scenario, we modeled an average annual temperature increase of $2.3-3.3^{\circ} \mathrm{C}$ and, an annual mean precipitation increase of $5-7 \%$ by 2050 in China [18].

\subsection{Geographic Data Sets}

For geographic background datasets, we downloaded the electronic map of China national boundary, province boundary and national grassland distribution from http://nfgis.nsdi.gov.cn/ at a scale of 1:4,000,000.

\subsection{Comparing Current and Climatic Change Scenarios}

In order to visualize the differences in the potential geographical distribution for $C$.italicus under current and future climate conditions, the respective suitable land and grassland areas for each EI category were calculated in ArcGIS for each scenario.

\subsection{Fitting CLIMEX Parameters}

To fit the CLIMEX model for $C$.italicus, the parameters were manually and iteratively adjusted until the simulated geographical distribution, as estimated by the EI values, coincided with the species' known native distribution and the reported description of its range. Due to the lack of the data we used the information for the related species Melanoplus sanguinipes (Fabricius) [19] to fit the initial values. Parameters used in the CLIMEX model are presented in table 1.

\section{Temperature Index}

The lower developmental threshold of $C$. italicus was $15.5^{\circ} \mathrm{C}$ [20]. In this paper, the minimum temperature for development (DV0) was set at $15.50^{\circ} \mathrm{C}$. The lower optimum temperatures for $C$. italicus's populations were set at $17^{\circ} \mathrm{C}$ to correspond to its distribution in northern Africa. Because this species is now established in Xinjiang province, so we set the upper threshold temperature to $35^{\circ} \mathrm{C}$ [21].

\section{Moisture Index}

To fit the known C. italicus's distribution in Xinjiang province, the lower soil moisture limit for development (SM0) was set to 0.01. We used this value because locusts normally require a desiccated environment for embryonic development. They survive well when the soil moisture in May is between 0.03-0.3 [22]. So in this paper, the lower and upper limits for optimal soil moisture (SM1 and SM2) were set to 0.03 and 0.3 respectively. Based on the $C$. italicus's distribution in the central Europe, the upper soil moisture limit for development (SM3) was set to 0.6. 
Table 1. Parameters used in the CLIMEX model for the $C$. italicus

\begin{tabular}{|c|c|c|}
\hline Parameter & $\begin{array}{l}\text { Initial } \\
\text { value }\end{array}$ & $\begin{array}{l}\text { Final } \\
\text { value }\end{array}$ \\
\hline DV0 Lower threshold temperature & $10.0^{\circ} \mathrm{C}$ & $15.5^{\circ} \mathrm{C}$ \\
\hline DV1 Lower optimum temperature & $16.0^{\circ} \mathrm{C}$ & $17.0^{\circ} \mathrm{C}$ \\
\hline DV2 Upper optimum temperature & $28.0^{\circ} \mathrm{C}$ & $28.0^{\circ} \mathrm{C}$ \\
\hline DV3 Upper threshold temperature & $32.0^{\circ} \mathrm{C}$ & $35.0^{\circ} \mathrm{C}$ \\
\hline SM0 Lower threshold of soil moisture & 0.02 & 0.01 \\
\hline SM1 Lower limit of optimum soil moisture & 0.05 & 0.03 \\
\hline SM2 Upper limit of optimum soil moisture & 0.30 & 0.30 \\
\hline SM3 Upper threshold of soil moisture & 0.70 & 0.60 \\
\hline DPD0 Diapause induction day length & $11 \mathrm{~h}$ & $10 \mathrm{~h}$ \\
\hline $\begin{array}{l}\text { DPT0 Diapause induction temperature } \\
\text { (average weekly minimum) }\end{array}$ & $11.0^{\circ} \mathrm{C}$ & $11.0^{\circ} \mathrm{C}$ \\
\hline $\begin{array}{l}\text { DPD1 Diapause termination temperature } \\
\text { (average weekly minimum) }\end{array}$ & $3.0^{\circ} \mathrm{C}$ & $6.0^{\circ} \mathrm{C}$ \\
\hline DPD Diapause development days & 120 & 90 \\
\hline $\begin{array}{l}\text { DPSW Summer or winter diapause } \\
\text { ('0' for winter diapause, ' } 1 \text { 'for summer diapause) }\end{array}$ & 0 & 0 \\
\hline TTCS Cold stress temperature threshold & $-18.0^{\circ} \mathrm{C}$ & $-18.0^{\circ} \mathrm{C}$ \\
\hline THCS Cold stress accumulation rate & -0.0004 & -0.0008 \\
\hline TTHS Heat stress temperature threshold & $35.0^{\circ} \mathrm{C}$ & $35.0^{\circ} \mathrm{C}$ \\
\hline THHS Heat stress accumulation rate & 0.008 & 0.0005 \\
\hline SMDS Dry stress soil moisture threshold & 0.020 & 0.010 \\
\hline HDS Dry stress accumulation rate & -0.003 & -0.003 \\
\hline SMWS Wet stress soil moisture threshold & 0.7 & 0.6 \\
\hline SMDS Dry stress soil moisture threshold & 0.001 & 0.003 \\
\hline
\end{tabular}

\section{Diapauses Index}

Diapause is an important biological characteristic that allows locust to survive harsh environmental conditions. Calliptamus italicus overwinters below ground in the egg stage[23]. Based on its distribution in Iran, Afghanistan [4], Tibet and Sichuan province, we set the diapause induction day length to 10 . We adjusted the diapauses parameters to identify suitable in areas in Xinjiang province based on C. italicus's distribution, north of the Mediterranean Sea, and north of Africa, based on that 
distribution, we set the diapause termination temperature and the diapause development days to 6 and 90 .

\section{Stress Parameter}

We adjusted the stress parameters to account for $C$. italicus' global distribution. This was done to reduce the likelihood that out prediction maps for climatic suitability would not include areas where $C$. italicus cannot survive.

\section{$3 \quad$ Results}

\subsection{Potential Geographical Distribution under Current Climate}

The CLIMEX parameter values were calibrated until the predicted geographical distribution agreed with the observed global distribution for $C$. italicus. With the current climate scenario our model predicted that North America, southern South America, most of the Europe, the edge of the Mediterranean Sea, isolated parts of north and south Africa, Central Asia, West Asia, East Asia and southern Australia were potentially suitable for $C$. italicus establishment (Figure 1). Known regions of occurrence, such as Italy, Spain, and Central Europe, with EIs between 0 and 20 were considered to have marginally suitable to suitable climates for establishment. Locations such as Kazakhstan, western Siberia, and Xinjiang where high population levels occur had EIs $>20$, and were considered optimally suitable for $C$. italicus.

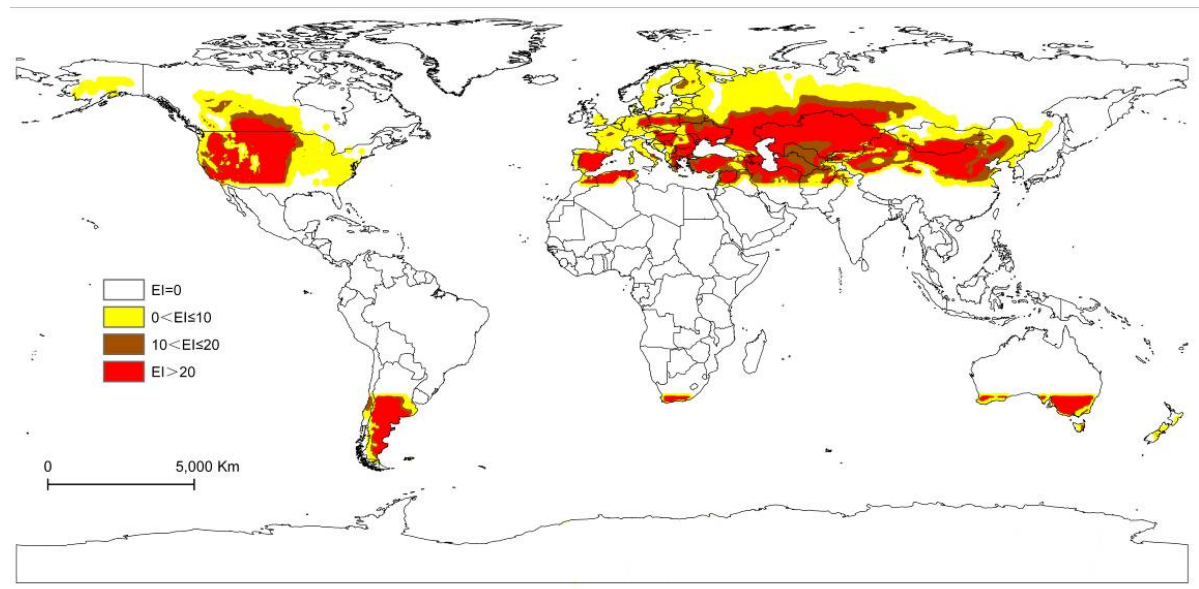

Fig. 1. The global Ecoclimatic Index (EI) values for $C$. italicus under the current climate scenario (1961-1990 averages) ( $\square$, unsuitable (0.00); $\square$, marginal (0.01-10); $\square$, suitable (10-20); $\square$, optimal (20.00+).) 
Our model predicted that, under current climatic conditions, C. italicus could establish north of the Yangtze River in approximately 29\% of China (Figure 2a). Optimal climate conditions occurred in most of Beijing, Tianjin, Xinjiang, Inner Mongolia, Gansu, Ningxia, Shaanxi, Shanxi, Hebei and small parts of Qinghai, Jilin, Shandong, and Henan. Climate conditions are projected to be marginal in parts of Heilongjiang, Jilin, Liaoning, Inner Mongolia, Gansu, Xinjiang, Qinghai, Shaanxi, Henan, Shandong, Anhui, Jiangsu, Sichuan and Hubei. The remaining areas south of the Yangtze River were unsuitable for the establishment of C. italicus. The grassland GIS layer further refined the model and estimated that (insert at-risk provinces here) were at risk for establishment based on climate and host presence (Figure 2b).

\subsection{Potential Geographical Distribution under Future Climate}

The climate change scenario indicated that China is likely to become hotter and wetter by 2050. As a result, the potential range for $C$. italicus is projected to expand. Under the climate change scenario, the percentage of China's land area and grassland area at risk for C. italicus establishment increased from $29 \%$ to $31 \%$ and $96 \%$ to $98 \%$, respectively. ,
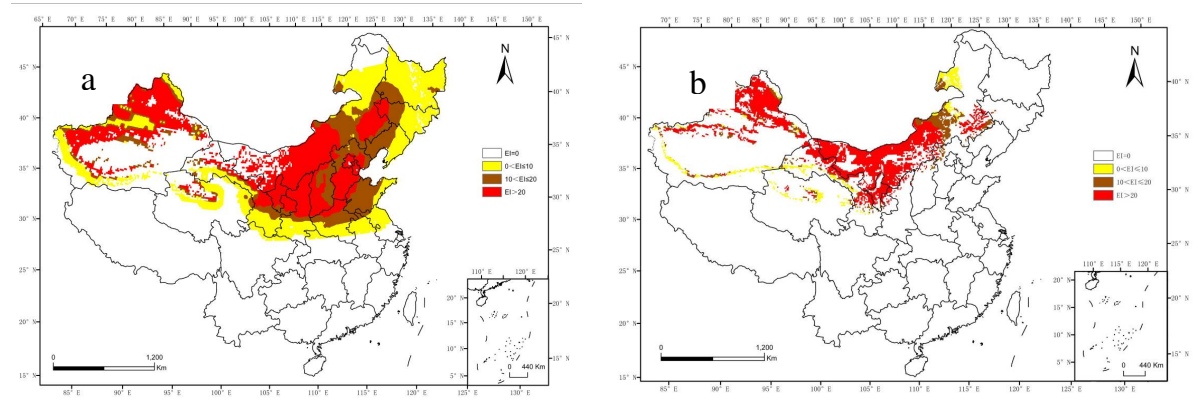

Fig. 2. The Ecoclimatic Index (EI) values for C. italicus in China under the current climate scenario (1961-1990 averages) with vegetation distribution ( $\square$, unsuitable (0.00); $\square$, marginal (0.01-10); $\square$, suitable (10-20); $\square$, optimal (20.00+).) ( a) for land area, b) for grassland area)

Also, the overall climate suitability of China's land area is projected to increase with climate change, especially in those areas with optimal climatic conditions (Figures 3). Our model predicted that by 2050, the proportion of the marginal areas will decrease from $9 \%$ to $7 \%$, suitable areas will decrease from $8 \%$ to $6 \%$, and optimal areas will increase $11 \%$ to $17 \%$. Therefore, the overall suitable area will increase by $2 \%$ by 2050 . For grassland, the proportion of the marginal areas will decrease from $10 \%$ to $4 \%$, suitable areas will decrease from $14 \%$ to $7 \%$, and the optimal areas will increase from $71 \%$ to $86 \%$, so the overall suitable area will increase by $2 \%$ by 2050 (Figure 4 ). 


\section{Discussion}

In this study, we combined Climex EI values with grassland host presence to increase the precision of the predictive maps. However, the model predictions discussed above surely have some limitations.

Additional factors like dispersal, host density, competition, and the effects of natural enemies [24], soil type, geographical barriers and human activities could be incorporated to generate more robust predictions. Also, the use of model evaluation techniques like the ROC curve [25] could be used to determine which modeling approaches, e.g. Maxent, GARP, DIVA-GIS and CLIMEX, are most appropriate for predicting the establishment potential of pests like $C$. italicus in a particular area.
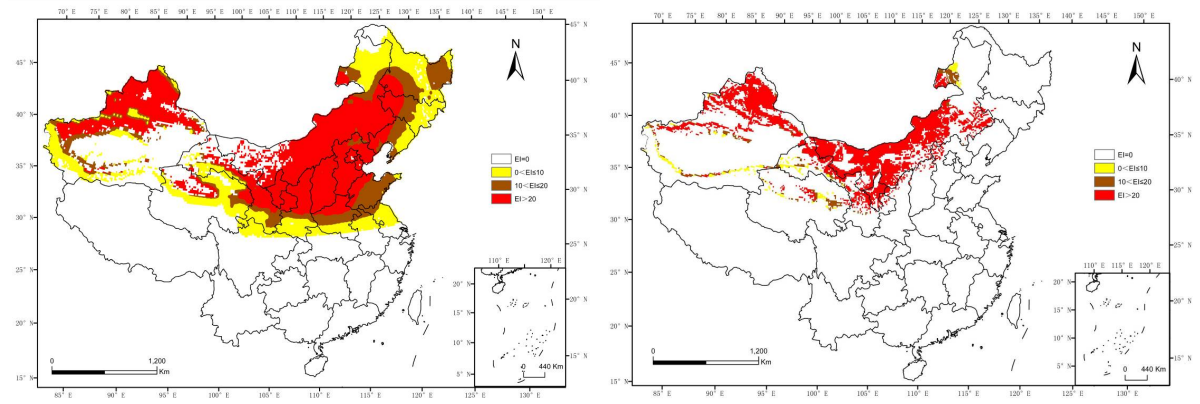

Fig. 3. The Ecoclimatic Index (EI) values for C. italicus in China in 2050 with vegetation distribution ( $\square$, unsuitable (0.00); $\square$, marginal (0.01-10); $\square$, suitable (10-20); $\square$, optimal $(20.00+)$.) ( a) for land area, b) for grassland area)
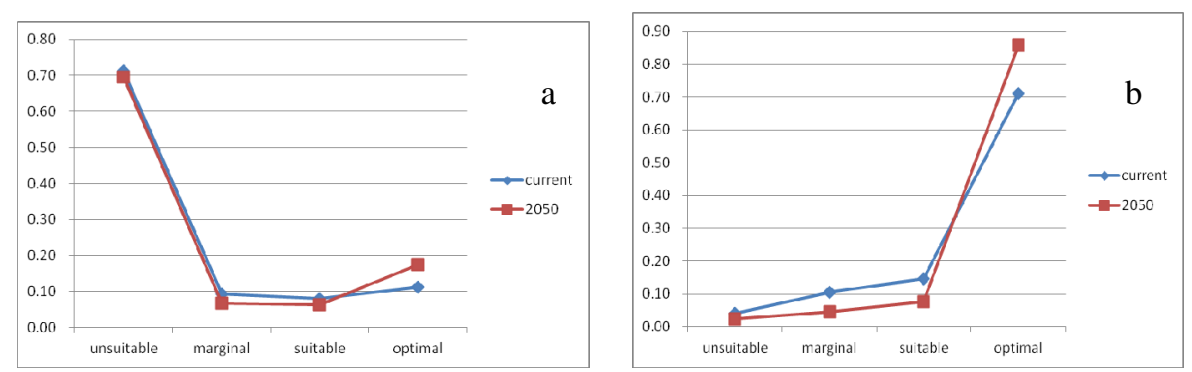

Fig. 4. Changes in area by EI category for total land area and grassland area under current and climate change scenarios ( a) for land area, b) for grassland area)

Acknowledgements. The authors would like to thank Zhimei Li and the other members of the Plant Quarantine Laboratory of China Agricultural University (CAUPQL). This study received financial support from the Special Fund for Agro-scientific Research in the Public Interest (201003079). 


\section{References}

1. Xue, Z.P., Zhang, Q., Yashen, S.L., Wang, G.J., Abudouwaili, Y.M.M., Xiao, H.W.: Food selection of Calliptamus italicus and loss assessment for the grassland. Plant Protection 36(1), 95-96 (2010) (in Chinese)

2. Antonow, A.G., Kambulin, V.E.: Forecasting seasonal dynamics of the Asiatic migratory locust using the Locusta migratoria migratoria-Phragmites australis forecasting system. In: New Strategies in Locust Control, pp. 81-89 (1997)

3. Zhang, Y., Gao, S., Yashen, S.L., Cao, G.C., Zhang, Z.H.: Numerical analyses on morphometrics gregarious and solitarious phase of Calliptamus italicus. Applied Entomology 48(4), 854-861 (2011) (in Chinese)

4. http://www. fao.org/ag/locusts-CCA/en/1010/1018/1075/

5. Zhang, S.M., Zhao, Y.X.: The geographical distribution of agricultural and forest insects in China. China Agriculture University Press, Beijing (1996) (in Chinese)

6. Crop Protection Compendium (2007)

7. Worner, S.P.: Ecoclimatic assessment of potential establishment of exotic pests. Journal of Economic Entomology 81, 973-983 (1988)

8. Ni, W.L., Li, Z.H., Chen, H.J., Wan, F.H., Qu, W.W., Zhang, Z., Kriticos, D.J.: Including climate change in pest risk assessment: the peach fruit fly, Bactrocera zonata (Diptera: Tephritidae). Bulletin of Entomological Research 10, 1-11 (2011)

9. Cheng, J.F.: The potential geographical distribution of Frankliniella occidentails Pergande based on CLIMEX and GIS in China. China Plant Protection 27(1), 16 (2007) (in Chinese)

10. Lin, W.: The potential geographical distribution of Hyphantria cunea in China. China Agriculture University, Beijing (1991) (in Chinese)

11. Chen, L.: The potential geographical distribution of Solenopsis invicta in China. Chinese Academy of Agricultural Sciences, Beijing (2007)

12. Qu, W.W., Li, Z.H., Huang, G.X., Lin, C.H., Ni, W.L.: The current and future potential geographic range of Corynespora Leaf Fall Disease in China. Sensor Lett. 10, 439-446 (2012)

13. Bourdôt, G.W., Lamoureaux, S.L., Watt, M.S., Manning, L.K., Kriticos, D.J.: The potential global distribution of the invasive weed Nassella neesiana under current and future climates. Biol. Invasions 6 (2010) 10.1007/s10530-010-9905-6

14. Kriticos, D.J., Sutherst, R.W., Brown, J.R., Adkins, S.W., Maywald, G.F.: Climate change and biotic invasions: a case history of a tropical woody vine. Biological Invasions 5, $145-165$ (2003)

15. Kriticos, D.J., Sutherst, R.W., Brown, J.R., Adkins, S.W., Maywald, G.F.: Climate change and the potential distribution of an invasive alien plant: Acacia nilotica ssp. indica in Australia. Journal of Applied Ecology 40, 111-124 (2003)

16. Sutherst, R.W., Maywald, G.F., Kriticos, D.J.: CLIMEX Version 3: User's Guide (2009), http: //www. Hearne.com. au

17. Kriticos, D.J., Alexander, N.S., Kolomeitz, S.M.: Predicting the potential geographic distribution of weeds in 2080. In: Preston, C., Watts, J.H., Crossman, N.P. (eds.) Proceedings of the Fifteenth Australian Weeds Conference, Adelaide, Australia, September 24-28, pp. 27-34. Weed Science Society of Victoria (2006)

18. Qin, D.H., Chen, Y.Y.: Climate and environment evolution in China. Science Press, Beijing (2005) (in Chinese) 
19. Olfert, O., Weiss, R.M., Kriticos, D.J.: Application of general circulation models to assess the potential impact of climate change on potential distribution and relative abundance of Melanoplus sanguinipes (Fabricius) (Orthoptera: Acrididae) in north American. Psyche, 1-9 (2011)

20. Wumaerbie, K., Xiong, L.: Determination of developmental zero and degree-days to complete one generation of Article black car locust, calliptamus italicus, Gomphocerus sibiricus. Xinjiang Animal Husbandry (suppl.), 30-31 (2007) (in Chinese)

21. Xi, R.H., Liu, J.P., Zhang, L., Ma, L.X.: The relationship between locusts lay eggs and climatic factor. Entomology Knowledge 28(2), 76-78 (1991) (in Chinese)

22. Guo, F., Chen, Y.L., Lu, B.L.: The biology of the migratory locusts in China. Shandong Science and Technology Press, Shandong (1991) (in Chinese)

23. Zhang, Q., Qiao, Z., Xiong, L., Bahatiyaer, D.W.T., Zhao, Y., Dang, H.C., Zhang, X.S., Xiao, H.W.: Biological characteristics of calliptamus italicus. Xinjiang Agriculture Sciences 6, 256 (1995) (in Chinese)

24. Baker, R.H.A., Sansford, C.E., Jarvis, C.H., Cannon, R.J.C., MacLeod, A., Walters, K.F.A.: The role of climate mapping in predicting the potential geographical distribution of non-indigenous pests under current and future climates. Agriculture Ecosystems and Environment 82, 57-71 (2000)

25. Wang, Y.S., Xie, B.Y., Wan, F.H., Xiao, Q.M., Dai, L.Y.: Application of ROC curve analysis in evaluating the performance of alien species' potential distribution models. Biodiversity Science 15(4), 365-372 (2007) 